\title{
Análisis de imágenes Landsat para la determinación de cambios de uso del suelo en un área de preservación ambiental (APA) en la zona de influencia de la ciudad de Brasilia (Brasil)
}

\author{
Landsat images analysis for the land cover change determination \\ in an environmental conservation area (APA) at the influence zone \\ of the city of Brasilia (Brazil)
}

\author{
José Imaña-Encinas ${ }^{1, \star}$, Edgar G. Banks-Machado², \\ Natália Oliveira-Ramos ${ }^{1}$ y Guillermo Riesco-Muñoz ${ }^{3}$
}

\begin{abstract}
Recibido: 04 abril 2019 | Aceptado: 03 noviembre 2019 | Publicado en línea: 15 diciembre 2019 Citación: Imaña-Encinas, J; Banks-Machado, EG; Oliveira-Ramos, N; Riesco-Muñoz, G. 2019. Análisis de imágenes Landsat para la determinación de cambios de uso del suelo en un área de preservación ambiental (APA) en la zona de influencia de la ciudad de Brasilia (Brasil). Revista Forestal del Perú 34(2): 163-171. DOI: http://dx.doi.org/10.21704/rfp.v34i2.1327
\end{abstract}

\begin{abstract}
Resumen
Se analizó la distribución de usos del suelo y su evolución más reciente en un área de preservación ambiental situada en la zona de influencia de la ciudad de Brasilia (Brasil). Para el análisis se emplearon imágenes satélite tomadas en 2002 y 2017 por los satélites Landsat 7 y Landsat 8 respectivamente. La superficie del área de preservación ambiental, junto con el área de amortiguamiento que la rodea (121 650 ha en total), se dividió en siete categorías de uso de suelo y una categoría correspondiente a masas de agua. En 2002 las superficies ocupadas por los diferentes tipos de uso de suelo se distribuían del siguiente modo: áreas agrícolas $29,15 \%$, áreas urbanas $24,45 \%$, campos $18,66 \%$, sabanas $15,59 \%$, bosques 7,68 \%, áreas de reforestación 1,34 \% y suelo expuesto 0,43\%. En 2017, 15 años más tarde, las superficies ocupadas eran: áreas agrícolas $36,90 \%$, áreas urbanas $26,08 \%$, campos $11,75 \%$, sabanas $8,11 \%$, bosques $8,25 \%$, áreas de reforestación 1,64 \% y suelo expuesto 4,50 \%. La mayor tasa de incremento fue la que se produjo para la categoría de suelo expuesto en tanto que la mayor variación en hectáreas por año fue la producida en la categoría de áreas agrícolas, que creció un 7,75 \% (incremento de 629 hectáreas por año). Considerando solamente el área de preservación ambiental (23 778 ha), la formación predominante eran las sabanas (26,39 \% del territorio) en tanto que las áreas agrícolas pasaban al segundo puesto, con el 20,89 \%.

Palabras clave: Cerrado, cobertura de suelo, conservación de la naturaleza, imagen satélite, Landsat, sabana, Teledetección, zona periurbana
\end{abstract}

\footnotetext{
${ }^{1}$ Universidad de Brasilia, Departamento de Ingeniería Forestal, Brasil.

${ }^{2}$ Agência Nacional de Águas, Superintendência de Planejamento de Recursos Hídricos, Brasil.

${ }^{3}$ Universidad de Santiago de Compostela, Escuela Politécnica Superior de Ingeniería, España.

* Autor de Correspondencia: imana@unb.br
} 

uso del suelo en un área de preservación ambiental en Brasilia

\begin{abstract}
The distribution of land uses and its most recent evolution in an environmental preservation area located in the area of influence of the city of Brasilia (Brazil) were analyzed. For the analysis, satellite images taken in 2002 and 2017 were used by Landsat 7 and Landsat 8 satellites respectively. The surface of the environmental preservation area and the surrounding buffer belt (an amount of 121650 ha) were divided into seven categories of land use and a category corresponding to water surfaces. In 2002, the areas occupied by the different types of land use were distributed as follows: agricultural areas $29.15 \%$, urban areas $24.45 \%$, fields $18.66 \%$, savannas $15.59 \%$, forests $7.68 \%$, planted forests $1.34 \%$ and bare soil $0.43 \%$. In 2017, 15 years later, the areas occupied were: agricultural areas $36.90 \%$, urban areas $26.08 \%$, fields $11.75 \%$, savannas $8.11 \%$, forests $8.25 \%$, planted forests $1.64 \%$ and bare soil $4.50 \%$. The highest rate of increment was that for the category of bare soil and the greatest variation in hectares per year was that produced in the category of agricultural areas, which grew by $7.75 \%$ (increase of 629 hectares per year). Considering only the environmental preservation area $(23778 \mathrm{ha})$, the predominant formations were the savannas ( $26.39 \%$ of the area) while the agricultural areas moved to second place, covering $20.89 \%$.
\end{abstract}

Key words: Cerrado, land cover, nature conservation, satellite image, Landsat, savannah, remote sensing, periurban area

\section{Introducción}

El Distrito Federal, donde está situada la ciudad de Brasilia (Brasil), ocupa una superficie de $5814 \mathrm{~km}^{2}$. El total de ese territorio se extiende en la región nuclear de las sabanas brasileñas, conocidas también como bioma Cerrado. Scariot et al. (2005) informan que el bioma de las sabanas brasileñas es mucho más rico en biodiversidad que las sabanas africanas. En el bioma Cerrado más de diez mil especies vegetales, cerca de 800 especies de aves y alrededor de 300 especies de mamíferos han sido identificados y debidamente clasificados (Ministério do Meio Ambiente 2016). Este bioma ocupa más de dos millones de kilómetros cuadrados, lo que corresponde al $23 \%$ del total de la superficie de Brasil (Klink y Machado 2005). A partir de la creación de la ciudad de Brasilia, actual capital del país, en 1961, las áreas naturales en el entorno de la metrópoli sufrieron enormes modificaciones en muy poco tiempo, hasta el punto de que en algunos lugares se llegó a la total extinción de la vegetación nativa (Strassburg et al. 2014; Strassburg et al. 2016). La ampliación de la frontera agrícola y ganadera, la inadecuada utilización de las técnicas de manejo del suelo, la apertura de áreas para actividades rurales, la creación de nuevos núcleos urbanos, el crecimiento urbano desordenado, la explotación irracional de los recursos naturales, los incendios forestales y las cortas no autorizadas de vegetación natural, representan serias preocupaciones para la preservación y mantenimiento de la biodiversidad existente en el bioma de las sabanas.

La definición de Área de Preservación Ambiental (APA), de acuerdo con el Sistema Brasileño de Unidades de Conservación Ambiental (Ministério do Meio Ambiente 2011), se refiere al uso del suelo en una unidad de conservación de uso sostenible. El Área de Preservación Ambiental denominada "APA Gama - Cabeza de Venado" cubre una superficie de 23778 ha y fue creada en abril de 1986 (Brasil, Brasilia, 1986). Se sitúa dentro del perímetro del Distrito Federal. El objetivo de esa creación era proteger los cursos de agua de las cuencas hidrográficas de los ríos Gama y Cabeza de Venado. Este área de preservación ambiental está localizada en el interior de la región central de la Reserva de la Biosfera del Cerrado, creada por la UNESCO en 1998 (UNESCO 2003). Se trata de un destacado espacio muy bien preservado y representativo de diversas fito-fisonomías de la sabana brasileña, en el que la prioridad es la captación de agua para 
el abastecimiento de la ciudad de Brasilia, que cuenta con más de tres millones de habitantes (Brasil 2017). Esas características fundamentaron la creación y mantenimiento de este área de preservación ambiental (Doyle 2009). Áreas de ocupación de la estación ecológica del Instituto Brasileño de Geografía y Estadística, la hacienda experimental de la Universidad de Brasilia y áreas naturales del Jardín Botánico de Brasilia, se hallan integradas en el área de protección ambiental Gama - Cabeza de Venado, compuesta además por zonas de usos $\mathrm{y}$ asentamientos humanos de bajo impacto ambiental. Áreas urbanas y núcleos rurales se sitúan en la zona de amortiguamiento (buffer o tampón), alrededor del perímetro del área de preservación ambiental, donde el uso del suelo debe atender rigurosamente a los objetivos de la Reserva de la Biosfera del Cerrado. Entre esos objetivos (UNESCO 2003) se menciona la preservación de la riqueza florística y faunística de la sabana localizada en el Distrito Federal, que actualmente sufre un fuerte deterioro. Incluso en algunas áreas están en proceso de extinción varias especies de la flora y la fauna silvestre de la región.

Para el estudio de áreas extensas en las que la cubierta vegetal es diversa, como es el caso del área de protección ambiental Gama - Cabeza de Venado y su zona de amortiguamiento, una poderosa herramienta de análisis son los sistemas de Teledetección, que se basan esencialmente en identificar y estudiar objetos a distancia a partir de la energía electromagnética que estos objetos reflejan o emiten. Los sensores remotos instalados en satélites o en otros dispositivos aéreos registran aquellas radiaciones electromagnéticas procedentes de la superficie de la Tierra que son suficientemente intensas para superar la capa filtrante que constituye la atmósfera. Las radiaciones de longitudes de onda corta $(0,4-3 \mu \mathrm{m})$ son las más útiles para el estudio de la cubierta vegetal, y corresponden a la energía solar reflejada por la vegetación y el suelo. Cuando existe una alta relación entre la radiación reflejada por una unidad de respuesta terrestre y una característica dasométrica, ambiental o de otro tipo, la imagen satélite se convierte en una fuente de información abun- dante y a bajo coste sobre las características de los recursos naturales (Álvarez González et al. 1995).

Los satélites estadounidenses de la serie Landsat ofrecen grandes posibilidades para el desarrollo de cartografía métrica y temática a partir de la información espacial. Barren toda la superficie terrestre cada 15 días, obteniendo información simultánea sobre áreas de $185 \times$ $170 \mathrm{~km}(31450$ km²), con una resolución de 15 $\mathrm{m}$ por píxel. Las secuencias temporales de imágenes permiten detectar los cambios operados sobre grandes extensiones de superficie de la Tierra a lo largo del tiempo, a fin de estudiar fenómenos a gran escala, como la degradación de los bosques o la deforestación (Álvarez González et al. 1995).

Los procedimientos de Teledetección se han transformado en una herramienta técnico-científica indispensable para cualquier sistema de planificación, gestión y manejo de los recursos naturales renovables (Chuvieco 2008). El satélite Landsat 7 fue lanzado al espacio en 1999 con objeto de monitorizar diversos recursos ambientales, desde el estado de las masas forestales de la Tierra hasta la calidad de los ríos. La comparación de las imágenes tomadas por este satélite en diferentes ocasiones así como la comparación con imágenes tomadas por otros satélites permitió conocer en qué cuantía retrocede la superficie ocupada por las selvas, el estado de las cosechas a nivel mundial o los cambios en el volumen de agua almacenada en ríos y lagos.

Un problema frecuente es plasmar sobre la cartografía disponible la información estratificada que se ha obtenido de la imagen satelital. Los sistemas de información geográfica permiten digitalizar en color dichas imágenes (que se comercializan en soporte fotográfico o bien en soporte digital) y superponer la imagen digital sobre la cartografía existente, ya que los satélites proporcionan imágenes con distorsión espacial despreciable (Álvarez González et al. 1995).

En ese contexto, el objetivo del presente trabajo consistió en identificar sobre una imagen del satélite Landsat 7 ETM+ del año 2002 
Análisis de imágenes Landsat para la determinación de cambios de uso del suelo en un área de preservación ambiental en Brasilia

y posteriormente en otra imagen del satélite Landsat 8 OLI del año 2017, las áreas ocupadas por ocho categorías de uso del suelo, analizando los cambios de superficies sobre las que se extienden los correspondientes paisajes naturales del Área de Preservación Ambiental Gama - Cabeza de Venado.

\section{Materiales y Métodos}

Para la elaboración de la base cartográfica fueron utilizados los archivos vectoriales del sistema cartográfico del Distrito Federal de Brasil. A partir de ellos se obtuvieron los archivos de mapas referentes a hidrografía, altimetría y malla viaria, a escala 1:25 000. La superficie ocupada en 2002 por el Área de Preservación Ambiental Gama - Cabeza de Venado y por una zona de amortiguamiento o zona buffer (tampón) de $10 \mathrm{~km}$ alrededor del perímetro del área de preservación fue extraída de la imagen proporcionada por el satélite Landsat 7, cuyo sensor es el ETM+ (Enhanced Thematic Mapper Plus), utilizándose para manejar la imagen el sistema de información geográfica SIG ArcView, módulo Image Analysis. El mismo sistema de información geográfica fue empleado para extraer la imagen de 2017, procedente del satélite Landsat 8 OLI ya que Landsat 7 solo tuvo una vida operativa de 5 años desde su lanzamiento en 1999. Se procedió a analizar la evolución del área de preservación ambiental y de su zona de amortiguamiento (Figura 1).

Como referencia para cartografiar el uso del suelo se utilizaron los mapas de suelos y de vegetación del Distrito Federal producidos en 2001. El mapa temático correspondiente fue obtenido mediante clasificación automática supervisada en campo haciendo uso del algoritmo de máxima verosimilitud tanto en 2002 (Meneses et al. 1995) como en 2017. Además, en 2017 se empleó también la metodología establecida por Chuvieco (2008). En cuanto a

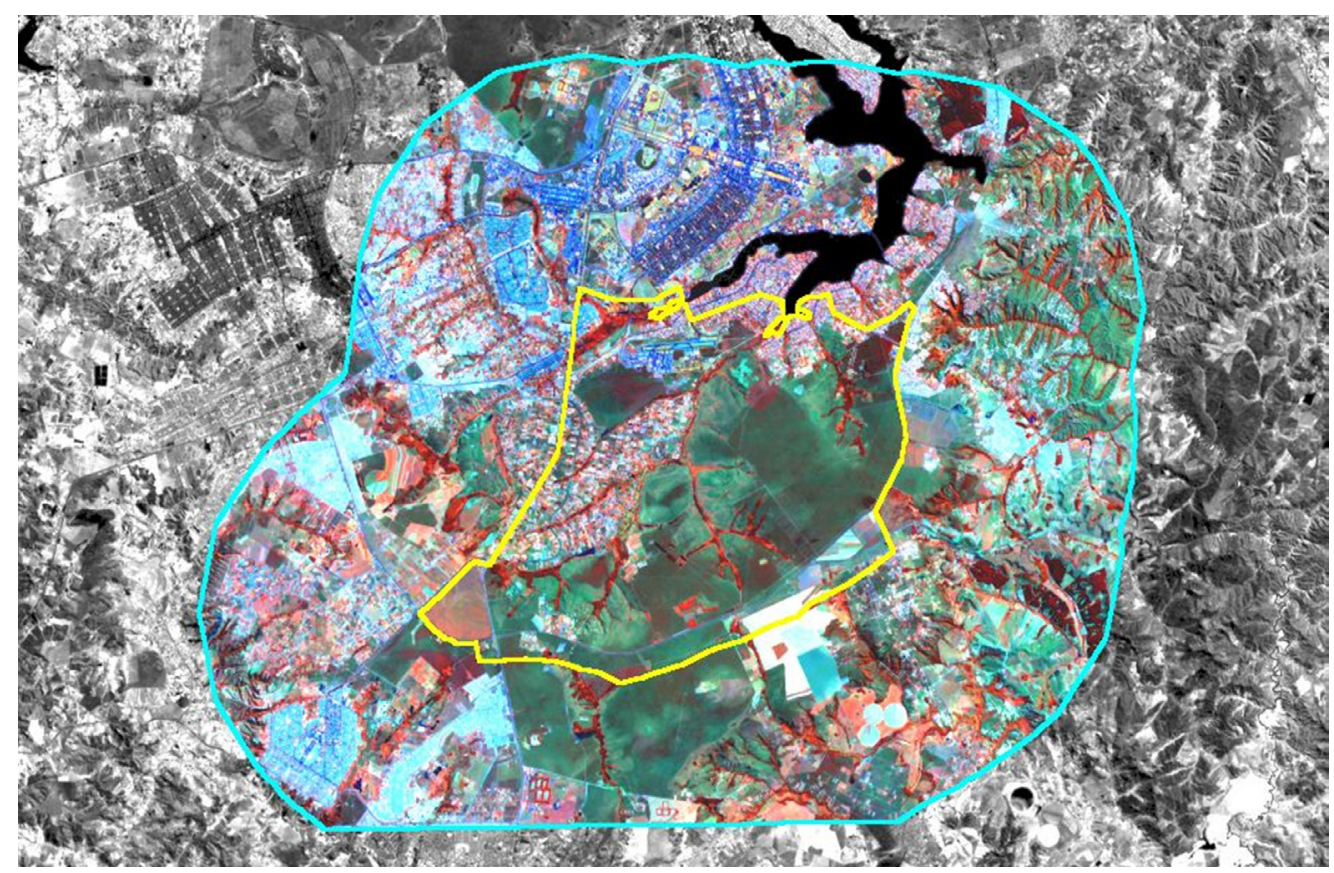

Figura 1. Carta Imagen del área de estudio en el año 2002. Composición colorida RGB 453. El perímetro marcado en amarillo corresponde a la zona núcleo del Área de Preservación Ambiental Gama - Cabeza de Venado, y el perímetro azul a la zona tampón de amortiguamiento. 
las clases de cobertura de suelo, considerando la proyección UTM Datum WGS 1984, se definieron las siguientes:

- "áreas agrícolas" (superficies ocupadas por cultivos agrícolas intensivos y granjas)

- “áreas urbanas” (superficies ocupadas por núcleos de población humana)

- "campos" (formaciones herbáceas de gramíneas, tanto naturales como plantadas)

- "sabanas" (fito-fisonomías de las comunidades vegetales conocidas en el Brasil como cerrado en sentido estricto, cerrado denso y cerrado ralo)

- "bosques" (formaciones forestales correspondientes a bosques ribereños, bosques secos y sabanas arboladas)

- "masas de agua"

- "reforestación" (superficies cubiertas con plantaciones de pinos y eucaliptos)

- "suelo expuesto" (áreas desnudas, sin cobertura vegetal).

La edición del mapa base fue realizada sobre la imagen Landsat 7 ETM+ de 2002, a escala 1:70 000. La cartografía de las zonas fue supervisada sobre el terreno con visitas de campo a 42 puntos preestablecidos con el objetivo de evaluar los resultados de la etapa de edición. En relación al año 2017, sobre la imagen Landsat 8 OLI a escala 1:60 000, la validación de la asignación de usos de suelo se hizo a través de la matriz de confusión y del índice Kappa, como medida de concordancia entre variables cualitativas, distribuyendo en toda la imagen 50 puntos muestrales de forma aleatoria. fue:

La ecuación para el cálculo del índice Kappa

$$
k=\frac{P_{1}-P_{2}}{1-P_{2}}
$$

Donde $\kappa=$ índice Kappa

$P_{1}=$ proporción de acuerdo entre las clasificaciones obtenidas sobre imagen satélite de 2017 y sobre el terreno.

$P_{2}=$ probabilidad de acuerdo entre clasificaciones debida al azar.
Se calculó la tasa promedio anual de cambio de las coberturas ( $r$ ), así como la superficie anual de cambio $(R)$, mediante las siguientes ecuaciones (Puyravaud 2003; Tapia Silva y López Flores 2017):

$$
\begin{gathered}
r=\frac{1}{t_{2}-t_{1}} \ln \frac{A_{2}}{A_{1}} \\
R=\frac{A_{1}-A_{2}}{t_{2}-t_{1}}
\end{gathered}
$$

Donde $t_{1}=$ tiempo inicial del periodo observado, $t_{2}=$ tiempo final,

$A_{1}=$ área inicial ocupada por la clase de cobertura observada, $A_{2}=$ área final.

\section{Resultados}

Fueron producidos diversos mapas a escala 1:100 000 descriptivos del uso del suelo en la región comprendida por el Área de Preservación Ambiental Gama - Cabeza de Venado y su área de influencia. Se identificó para cada año de análisis (2002 y 2017) la superficie ocupada por cada una de las ocho categorías preestablecidas, y enumeradas en el capítulo de Material y Métodos, siendo los valores los que aparecen en el Cuadro 1. Se observa que tanto en 2002 como en 2017 el uso del suelo más abundante era el correspondiente a áreas agrícolas, seguidas en importancia por las áreas urbanas. Mientras que en 2002 ambos tipos de uso del suelo representaban el $54 \%$ del territorio, en 2017 pasaban a constituir el 63 \%. Este incremento se produjo tanto en superficie urbana como agrícola aunque el incremento de la superficie agrícola fue mucho más destacado (629 ha/año). De hecho, esta es la mayor variación detectada en el periodo en términos absolutos para todas las clases de cobertura del área de estudio. Se observó que las sabanas perdieron 606 ha/año en promedio, que fueron probablemente transformadas en áreas agrícolas, siguiendo la filosofía y análisis de los cambios del paisaje natural de varios autores (Dantas et al. 2015; Forman y Gordon 1986). En el periodo considerado solo pierden terreno los campos y sabanas. 

uso del suelo en un área de preservación ambiental en Brasilia

En términos relativos la mayor variación es, con gran diferencia, la que se da en cuanto a incremento de la presencia de suelos desnudos, cuya tasa de variación media anual $(r=0,156)$ fue positiva y la más alta de todas las categorías de uso del suelo analizadas, dado que el valor de partida era muy reducido. Con todo, el incremento en términos absolutos de esta categoría fue considerable (un promedio de 330 ha/año), el segundo más importante después de la clase de áreas agrícolas.
Centrando el análisis en los datos más recientes del área de preservación ambiental (sin contar la zona de amortiguamiento), las sabanas constituyen la mayor parte de la cobertura (el $26 \%$ de las 23778 ha totales), pasando las áreas agrícolas y urbanas a los puestos segundo y tercero respectivamente (Cuadro 2). Entre áreas agrícolas y urbanas solamente suman el 40 \% de la extensión del área de preservación ambiental mientras que ascienden al $63 \%$ que se indicó si se tiene en cuenta el área de amortiguamiento.

\begin{tabular}{|c|c|c|c|c|c|c|}
\hline \multirow[t]{2}{*}{ Clase de uso del suelo } & \multicolumn{2}{|c|}{$\begin{array}{c}\text { Superficie ocupada en } \\
2002 \\
\end{array}$} & \multicolumn{2}{|c|}{$\begin{array}{c}\text { Superficie ocupada en } \\
2017 \\
\end{array}$} & \multirow{2}{*}{$r$ anual } & \multirow{2}{*}{$\begin{array}{c}R \\
\text { (ha/año) }\end{array}$} \\
\hline & ha & $\%$ & ha & $\%$ & & \\
\hline Áreas agrícolas & 35461 & 29,15 & 44889 & 36,90 & $+0,016$ & 629 \\
\hline Áreas urbanas & 29743 & 24,45 & 31732 & 26,08 & $+0,004$ & 133 \\
\hline Campos & 22700 & 18,66 & 14289 & 11,75 & $-0,031$ & -561 \\
\hline Sabanas & 18965 & 15,59 & 9871 & 8,11 & $-0,044$ & -606 \\
\hline Bosques & 9343 & 7,68 & 10040 & 8,25 & $+0,005$ & 46 \\
\hline Masas de agua & 3285 & 2,70 & 3359 & 2,76 & $+0,001$ & 5 \\
\hline Reforestación & 1630 & 1,34 & 2000 & 1,64 & $+0,014$ & 25 \\
\hline Suelo expuesto & 523 & 0,43 & 5470 & 4,50 & $+0,156$ & 330 \\
\hline Total & 121650 & 100,00 & 121650 & 100,00 & & 0 \\
\hline
\end{tabular}

Cuadro 1. Categorías de uso del suelo en porcentaje del Área de Preservación Ambiental Gama - Cabeza de Venado y zona de amortiguamiento, con los respectivos cambios anuales.

\begin{tabular}{lcc}
\hline Clase de uso del suelo & ha & \% \\
\hline Áreas agrícolas & 4967,55 & 20,89 \\
Áreas urbanas & 4617,96 & 19,42 \\
Campos & 4480,36 & 18,84 \\
Sabanas & 6275,84 & 26,39 \\
Bosques & 2237,41 & 9,41 \\
Masas de agua & 33,44 & 0,14 \\
Reforestación & 331,63 & 1,39 \\
Suelo expuesto & 834,30 & 3,51 \\
\hline Total & 23778,49 & 100,00 \\
\hline
\end{tabular}

Cuadro 2. Categorías de uso del suelo en porcentaje de la zona núcleo del Área de Preservación Ambiental Gama-Cabeza de Venado para 2017. 


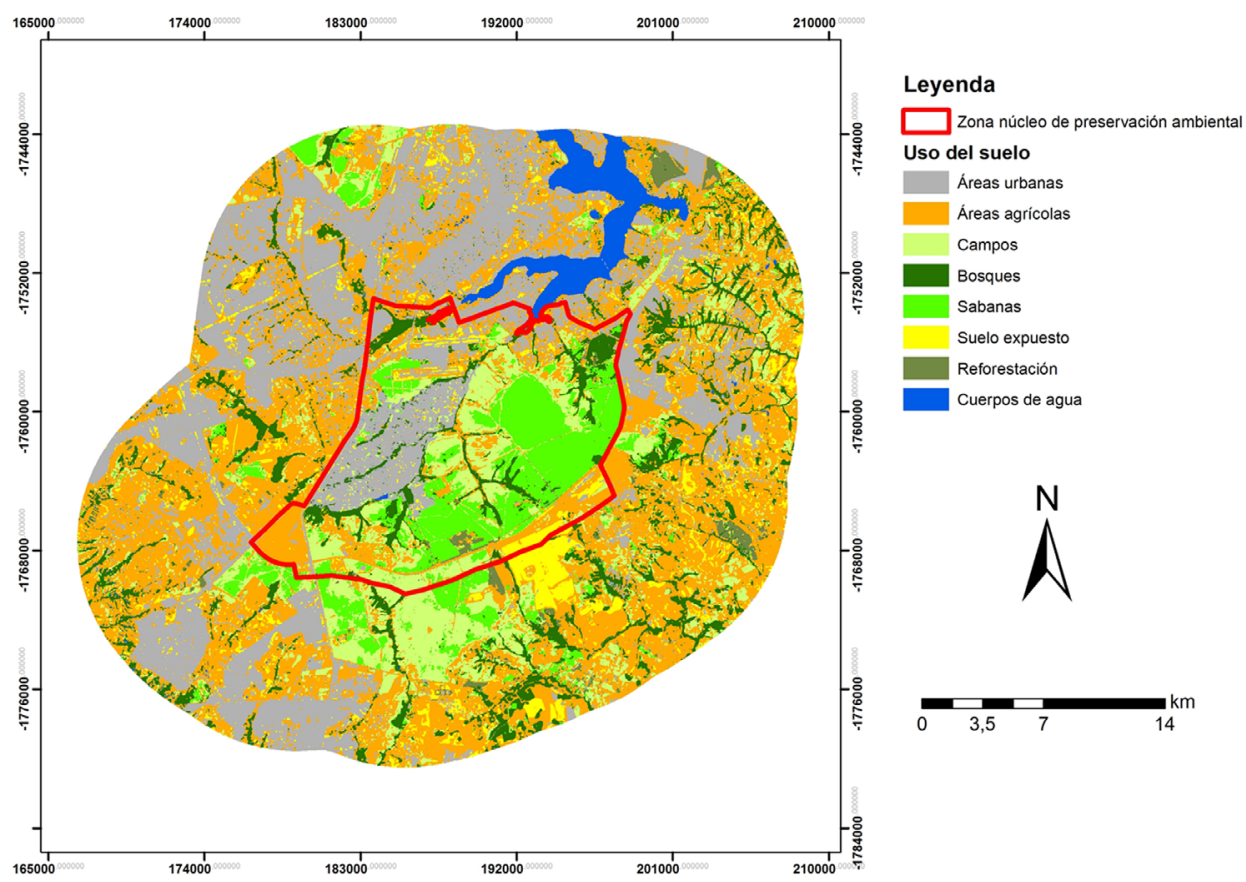

Figura 2. Distribución de la cobertura del suelo en el año 2017 en el Área de Preservación Ambiental Gama Cabeza de Venado y en la zona tampón.

\section{Discusión}

La validación de la clasificación de 2017 presentó una precisión global de 0,74 y un índice Kappa de 0,67, que se consideraron muy satisfactorios de acuerdo con los criterios de clasificación de Chuvieco (2008) y Fonseca (2000).

Los resultados muestran, para el año 2002, que la mayor parte de la superficie en el Área de Preservación Ambiental Gama - Cabeza de Venado y su zona de amortiguamiento, fue clasificada en la categoría áreas agrícolas (Cuadro 1). Estas áreas mostraron múltiples actividades propias del sector agrícola, que aumentaron y continuarán aumentando por la presión antrópica, concentrada principalmente en la zona de amortiguamiento. La vegetación autóctona presente en la zona de amortiguamiento fue modificada significativamente. En 2017 la mayor superficie del área de preservación ambiental continuaba en la categoría áreas agríco- las, que se había incrementado en un 7,75 \%. Se redujo un 7,48 \% la cobertura de áreas de sabanas y de 6,91\% en las áreas de campos. Aumentó significativamente la presencia de áreas de suelo expuesto (4,07\%), probablemente por usos agrícolas inadecuados. Las zonas con vegetación nativa se redujeron, siendo substituidas principalmente por áreas agrícolas. El clasificador detectó la presencia de áreas agrícolas dentro de ambientes urbanos posiblemente por la presencia de áreas verdes ajardinadas y árboles fuera del bosque (Trees Outside the Forests), que representan la arborización de las áreas urbanas (Foresta et al. 2013). Sin embargo, el Área de Preservación Ambiental Gama - Cabeza de Venado (sin tener en cuenta el área de amortiguamiento) presenta bien conservada cerca del $55 \%$ de su superficie vegetal nativa.

En el periodo considerado la mayor pérdida de territorio se ha producido en terrenos de 

uso del suelo en un área de preservación ambiental en Brasilia

campos y sabanas (Cuadros 1 y 2), en tanto que ha aumentado la presencia de terrenos agrícolas, urbanos y suelos desnudos. Esto indica que el incremento de los usos del suelo en los que es mayor la influencia del hombre se está produciendo a costa de los terrenos con vegetación de herbazales, sin pérdida de superficie de bosques, que incluso experimenta un cierto incremento durante los 15 años de observación.

La comparación de resultados entre los años 2002 y 2017 está sujeta a cierta incertidumbre y debe tomarse con cautela dado que las imágenes que constituyen la fuente de la información no son totalmente comparables ya que proceden de distintos sensores instalados en diferentes satélites. No obstante, la evolución que se aprecia en el periodo es muy diferente entre las ocho categorías analizadas, haciendo especial énfasis en este trabajo en aquellos cambios más destacados.

\section{Conclusiones}

El empleo de imágenes procedentes del satélite Landsat 7 para la identificación del uso del suelo y para su asignación a clases de cobertura vegetal permiten obtener resultados suficientemente precisos. Las imágenes satelitales empleadas constituyen también una herramienta eficaz para detectar cambios en la distribución de la vegetación en el vasto territorio ocupado por la sabana brasileña. Los mapas de uso y ocupación del suelo entre 2002 y 2017 revelaron significativos cambios de superficie (incremento de las zonas de intervención humana a costa de campos y sabanas), lo que obliga a implantar políticas públicas dirigidas a establecer mayores sistemas de monitorización, control y administración ambiental gubernamental.

\section{Bibliografía}

Álvarez González, JG; Ruiz González, AD.; Riesco Muñoz, G. 1995. Inventario Forestal por Fotografía Aérea y Teledetección. Escuela Politécnica Superior de Lugo. 57 p.

Brasil (Fundação Instituto Brasileiro de Geografia e Estatística). 2017. Resolução 4 de
28 de agosto de 2017. Brasília: Diário Oficial da União, Seção 1, número 167 de 30 de agosto de 2017, p.57.

Brasil (Brasília). 1986. Decreto no 9417 de 21 de abril de 1986. Brasília: Diário Oficial do Distrito Federal de 24 de abril de 1986, ano X, no 76.

Chuvieco, E. 2008. Teledetección ambiental, la observación de la tierra desde el espacio. Barcelona: Editorial Ariel, Ciencia. 542 p.

Dantas, ME; Armesto, RCG; Silva, CRda; Shinzato, E. 2015. Geodiversidade e análise da paisagem. uma abordagem técnico-metodológica. Terrae Didática 11(1):4-13.

Doyle, PMMC. 2009. Reserva da Biosfera do Cerrado no Distrito Federal. Brasilia: Ministério do Meio Ambiente (MMA). 35 p.

Fonseca, LMG. 2000. Processamento digital de imagens. Instituto Nacional de Pesquisas Espaciais (INPE). $105 \mathrm{p}$.

Foresta, H; Somarriba Chávez, E; Temu, A; Boulanger, D; Feuily, H; Gauthier, M. 2013. Towards the assessment of trees outside forests. Roma: FAO. 345 p.

Forman, RTT; Gordon, M. 1986. Landscape ecology. New York: Wiley. 619 p.

Klink, CA; Machado, RB. 2005. A conservação do cerrado brasileiro. Megadiversidade 1(1):147-155.

Meneses, PR; Assad, ED; Sano, EE. 1995. Introdução ao processamento de imagens digitais de satélite e sensoriamento remoto. Brasília: Editora Universidade de Brasília. 96 p.

Ministério do Meio Ambiente. 2011. Sistema Nacional de Unidades de Conservação da Natureza. Brasília: Serviço Brasileiro Florestal. 76 p.

Ministério do Meio Ambiente. 2016. Estratégia do Programa Nacional de Monitoramento Ambiental dos Biomas Brasileiros. Brasília: MMA/ Secretaria de Biodiversidade e Florestas. 44 p.

Puyravaud, JF. 2003. Standardizing the calculation of the annual rate of deforestation. Forest Ecology and Management 117:593-596. 
Scariot, A; Sousa-Silva, JC; Felfili, JM. 2005. Cerrado: ecologia, biodiversidade e conservação. Brasília: Ministério do Meio Ambiente. $439 \mathrm{p}$.

Strassburg, BBN; Latawiec, AE; Balmford, A. 2016. Brazil: urgent action on Cerrado extinction. Nature 540:199.

Strassburg, BBN; Latawiec, AE; Barioni, LG; Nobre, CA; Silva, VPda; Valetim, JF; Vianna, M; Assad, ED. 2014. When enough should be enough: improving the use of current agricultural lands could meet production demands and spare natural habitats in Brazil. Global Environmental Change 28:84-97.

Tapia Silva, FO; López Flores, E. 2017. Variabilidad espacio-temporal de la cobertura terrestre en la cuenca del rio Tecolutla, México. GeoFocus (Artículos) 20:163-182.

UNESCO (Organización de las Naciones Unidas para la Educación, Ciencia y Cultura, Brasil). 2003. Subsídios ao zoneamento da APA Gama - Cabeça-de-Veado e Reserva da Biosfera do Cerrado; caracterização e conflitos socioambientais. Brasília: UNESCO/MAB. 176 p. 